\title{
Task-Based Writing to Improve Young Teenage Learners’ Reading Skills
}

\author{
Mehran Esfandiari ${ }^{1, *}$ \\ ${ }^{1}$ School of Education, The University of Nottingham, Nottingham, The UK \\ *Correspondence: School of Education, The University of Nottingham, Nottingham, Nottinghamshire, NG8 1BB, \\ The UK. E-mail: ttxme19@nottingham.ac.uk
}

Received: February 13, 2014 Accepted: February 28, $2014 \quad$ Online Published: March 10, 2014

doi:10.5430/wjel.v4n1p20 URL: http://dx.doi.org/10.5430/wjel.v4n1p20

\begin{abstract}
Following the shift from traditional teacher-fronted towards learner-centered approaches to language teaching, the idea that languages are acquired through authentic acts of communication is now widely accepted as a central tenet of language teaching methodology. As a strong version of Communicative Language Teaching (CLT), Task-Based Learning (TBL) lays great emphasis on language use and entails using the English language in order to acquire it. Of the four language skills, it is possibly writing that has had the least attention paid to its role in fostering language acquisition, though some kind of reciprocal interrelationship has been acknowledged between reading and writing. Reporting on a quasi-experimental study, this paper presents an investigation into the impact of task-based writing on young teenage EFL learners' reading skills. It suggests that task-based writing helps such learners make improvements in their skills of reading for gist, specific information, and detailed comprehension to a significantly measurable extent.
\end{abstract}

Keywords: task-based writing; reading skills; CLT; TBL; teenage learners; EFL learners

\section{Introduction}

The belief that languages are acquired through communication resulted in the shift from language knowledge towards language use. Following its emergence as a British innovation in the field of Second Language Acquisition (SLA), Communicative Language Teaching (CLT) has been earning itself a worldwide reputation for effectiveness. As a logical development of CLT, Task-based Learning (TBL) places great emphasis on interaction and practical purposes for which language must be used (Brown, 2001). That is to say, it entails using the English language to acquire it.

When it comes to language skills, enough value has not been attached to the role that writing can play in language learning (Littlejohn, 1991), though there has always been an attempt to explore effective approaches to language teaching. It is important to note that a kind of bi-directional connection has been acknowledged between reading and writing as two of the four language skills (Stotsky, 1983; Carson and Leki, 1993). However, there is a lack of significant empirical evidence about the nature of such a relationship.

The aim of this study is to present the results of a case study into the impact of task-based writing on the reading skills and sub-skills of young teenage EFL learners. In doing so, it suggests that task-based writing helps such learners to make improvements in reading for gist, specific information, and detailed comprehension.

\section{Literature Review}

Following the shift from traditional teacher-fronted towards more learner-centered approaches to teaching, there has been a growing tendency towards CLT. Building on the claim that languages are acquired through authentic acts of communication and negotiation of meaning (Richards, 2006), TBL has come into widespread use as a strong version of CLT. With its main focus on fluency rather than accuracy, it helps learners to discover the system of a language as they learn how to communicate in that language. Simply stated, learners learn a language by using it (Howatt and Widdowson, 2004). Having defined tasks as goal-oriented activities for achieving an outcome, Willis (1996) 
established a framework for TBL, which is comprised of three phases - that is, 'pre-task', 'the task cycle', and 'the language focus'.

Where language learning is concerned, a large number of studies have been conducted to explore effective approaches to teaching writing as a language skill. However, it is important to note that

"Writing is unfortunately very commonly used as a means of evaluation so it is not surprising that many people feel they are being judged when they are asked to write something” (Littlejohn, 1991:81).

It can be argued that of the four language skills, it is possibly writing that has had the least attention paid to its role in fostering language acquisition. Indeed, as a means of developing the general ability of language learners, significance has not been attached to this particular language skill (Littlejohn, 1991).

It is interesting to note that a number of authorities claim that some kind of bi-directional relationship should exist between reading and writing as two of the four language skills. There is the belief that good readers are good writers (Stotsky, 1983), and the two skills seem interactive and interdependent (Carson and Leki, 1993). In addition, there is the idea that when it comes to meta-cognitive awareness, conscious-raising writing tasks can pave the way for language learning and improvements in reading skills (Guterman, 2003). Therefore, it might be argued that if task-based writing activities are combined with reading instruction, it might result in a big difference being made to the reading skills of language learners. This is because as a result of such tasks, they are required to write for, to, and with other learners. Thus, such interaction can facilitate the production of more syntactically and lexically complex texts (Li, 2000).

\section{Context Setting}

The study was conducted in Neek English Language Institute, which is one of the authorized Cambridge ESOL Examinations centers in Iran. Based on the Common European Framework of Reference for Languages (CEFR), the centre runs a broad range of General English courses for a growing population of young learners and teenagers who wish to acquire a good command of the English language. As part of their terms and conditions, learners are required to sit Cambridge ESOL exams to be able to move up through the system. Young teenage learners aged between 13 and 15 take part-time evening courses at this centre in blocks of ten weeks throughout the academic year. They attend two 90-minute sessions every week, where English lessons are delivered to them from a four-level series of books called Take Off, specifically designed for young teenagers by Longman Pearson. It should be mentioned that the subjects of this study had Take Off 2 as their course book.

From my experience as an ESOL examiner, the majority of these young candidates find reading papers quite challenging. Therefore, I decided to conduct a quasi-experimental study to find out whether or not task-based writing instruction can make any difference to their reading skills. For the purpose of this study, two books were selected. A significant number of the task-based activities were adapted from CAMBRIDGE Skills for fluency: WRITING 1 by Andrew Littlejohn (1991), and some others were taken from Writing Extra: A Resource Book of Multi-Level Skills Activities (Cambridge Copy Collection) by Graham Palmer (2004). Since both of the books are topic-based, it was a straightforward task to opt for the topics that could easily match those of their course book to a significant extent.

\section{Research Design}

A quasi-experimental study was conducted over a ten-week period in Neek English Language Institute with a control group, an experimental group, a pre-test and a post-test. To ensure that both of the groups would benefit from equivalent conditions, a great deal of attention was paid to the timetabling, process of random sampling, and use of reliable tests. In addition, the t-Test was applied at the outset of the study to ensure internal reliability.

Since a significant number of the young teenage learners at the above centre were preparing themselves for Key English Test (KET) for Schools, the reading paper of this Cambridge ESOL exam was selected as the data collection instrument. This paper, which consists of five parts, requires candidates to answer a total of 35 questions. The task focus in each part is almost entirely different from the other four. In part one, questions one to five, candidates deal with gist reading of real-world notices - that is, reading for main message. In part two, questions six to ten, significance is attached to reading and identifying appropriate vocabulary. In part three, questions 11 to 20, the main focus is on functional language - that is, reading and identifying appropriate response. In part four, questions 21 to 27, candidates are involved in reading for detailed understanding and main ideas. And finally in part five, questions 28 to 35, value is attached to reading and identifying appropriate structural word. 
It can be argued that such papers pave the way for the achievement of more reliable results as they are rigorously validated by University of Cambridge Local Examinations Syndicate (UCLES) to ensure that they perfectly satisfy standards in terms of authentic assessment and communicative language testing. Therefore, two past papers were chosen from Cambridge KET for Schools Handbook for Teachers to be used as the pre-test, paper one, and post-test, paper two.

\section{Participants and Sampling}

In the Islamic Republic of Iran, there is no such thing as co-education at the primary and secondary level. Therefore, the subjects of this study were 22 male teenage learners in Neek English Language Institute who were making preparations to sit Cambridge KET for Schools. All of them were from Esfahan, the second largest city in Iran, and spoke Persian as their first language. It is important to note that they seemed to be a homogenous group at the elementary level as they all had just passed Cambridge English YLE Flyers, the highest level of Cambridge ESOL exams for young learners, with flying colors. Thus, they were divided into half. Student details are summarized below in Table 1.

Table 1. Student Details

\begin{tabular}{ccc}
\hline & 13 to 14-year-olds & 14 to 15-year-olds \\
\hline Group A & 6 & 5 \\
Group B & 5 & 6 \\
\hline Total & $\mathbf{1 1}$ & $\mathbf{1 1}$ \\
\hline
\end{tabular}

At the next stage, both of the groups were asked to sit the pre-test, paper one. Table 2 shows the mean score of each group for different parts of the pre-test.

Table 2. Mean Scores for Different Parts of the Pre-test

\begin{tabular}{lccccc}
\hline & Part 1 & Part 2 & Part 3 & Part 4 & Part 5 \\
& $(\mathbf{Q}$ 1-5) & $\mathbf{( Q . 6 - 1 0 )}$ & $\mathbf{( Q . ~ 1 1 - 2 0 )}$ & $\mathbf{( Q . ~ 2 1 - 2 7 )}$ & $\mathbf{( Q . 2 8 - 3 5 )}$ \\
\hline Group A & 2.15 & 1.76 & 3.01 & 1.89 & 3.02 \\
Group B & 2.24 & 1.85 & 3.06 & 1.86 & 3.07 \\
\hline
\end{tabular}

To ensure internal reliability, it was necessary to draw a comparison between the total mean scores of the two groups. Therefore, the pre-test results were analyzed through the t-Test. Table 3 summarizes the calculations for the t-Test.

Table 3. Calculations for the t-Test

\begin{tabular}{lccc}
\hline & Mean & SD & SE \\
\hline Group A & 11.83 & 2.88 & 0.83 \\
Group B & 12.08 & 3.08 & 0.88 \\
\hline
\end{tabular}

Having calculated the t-value to be 0.2, set the alpha level (the risk level) at 0.05 , and determined the degree of freedom (df), 20, the t-value can be looked up in a standard table of significance. From a statistical point of view, the $\mathrm{t}$-value is small and no marked difference can be found between the means of the two groups. That is to say, the samples had been drawn from the same population. Thus, Group A and B made the control and experimental group, respectively.

\section{Procedure}

An additional one-hour session was arranged for each of the two groups over the ten-week period of their course. The same male tutor delivered lessons to the participants. However, the lesson plans for these two extra sessions were thoroughly different. While the control group was revising the work that had been done in their classes during the week, the experimental group was engaged in task-based writing activities.

It should also be mentioned that for the purpose of this study, the framework recommended by Jane Willis in the year 1996 for TBL was used as the main basis of instruction. In order for the three phases of the TBL lesson - pre-task, the task cycle, and the language focus - to be put into practice properly, three separate handouts were prepared for each session. 


\section{Structure of Each Lesson}

Since the main aim of the lesson was to use the English language to write in English, students were asked not to share their first language. However, a few bilingual dictionaries for young learners were taken to the class to avoid a breakdown in communication. The lesson was comprised of three stages as follows:

\subsection{Pre-Task}

Before giving out the text, the task had to be set by the tutor, whom was encouraged to use not only the silent approach, but also body language to introduce the topic of the lesson preferably through eliciting. Then, students were given the first handout, on which they were instructed to do a few successive writing activities in pairs. Although the main aim of this stage was to help learners to recall some useful chunks of language and expand their knowledge of related vocabulary items in authentic situations, the majority of utterances were in the form of short sentences.

\subsection{The Task Cycle}

The main task - the second handout - was given to the students, asking for longer utterances in authentic situations in writing. However, learners were asked to respond in the form of a pyramid discussion while being monitored by the tutor. Simply stated, they were first required to undertake the writing task in small groups and come to an agreement as a group. They were then instructed to form progressively larger groups by reaching an agreement at each stage until finally the whole class was involved in producing one piece of written work as the final outcome.

Such an organizational technique resulted in a significant amount of language being shared through interaction, negotiation of meaning, and collaboration. Furthermore, in order for learners to be capable of presenting their reports to each other in a larger group, everyone was involved in rehearsing reports and drafting written versions.

\subsection{The Language Focus}

At the final stage, the third handout was given to the students, and they were instructed to do another writing practice activity in pairs. However, the main aim of this stage was to enable students to reflect on the language they had experienced through in-depth analysis of the forms and lexical items. In terms of error correction, priority was given to self and peer correction, and teacher correction was encouraged only as a last resort.

\section{Results}

The above structure was followed for every lesson with the experimental group. At the end of the 10-week block, both the control group and the experimental group sat the post-test, paper two. Table 4 shows the mean score of each group for different parts of the post-test.

Table 4. Mean Scores for Different Parts of the Post-Test

\begin{tabular}{lccccc}
\hline & Part 1 & Part 2 & Part 3 & Part 4 & Part 5 \\
& $(\mathbf{Q}$. 1-5) & $\mathbf{( Q . 6 - 1 0 )}$ & $\mathbf{( Q . 1 1 - 2 0 )}$ & $\mathbf{( Q . ~ 2 1 - 2 7 ) ~}$ & $\mathbf{( Q . 2 8 - 3 5 )}$ \\
\hline Control Group & 2.81 & 2.68 & 7.36 & 2.76 & 7.80 \\
Experimental Group & 4.09 & 3.91 & 7.36 & 4.02 & 7.62 \\
\hline
\end{tabular}

Like the pre-test, a comparison had to be drawn between the total mean score of the control group and that of the experimental group. Thus, the results of the post-test were painstakingly analyzed through the t-Test. Table 5 summarizes the calculations for the t-Test.

Table 5. Calculations for the t-Test

\begin{tabular}{cccc}
\hline & Mean & SD & SE \\
\hline $\begin{array}{c}\text { Control Group } \\
\text { (Group A) }\end{array}$ & 23.41 & 2.74 & 0.79 \\
$\begin{array}{c}\text { Experimental Group } \\
\text { (Group B) }\end{array}$ & 27.00 & 2.59 & 0.74 \\
\hline
\end{tabular}

Having calculated the t-value to be 3.30, set the alpha level (the risk level) at 0.05 , and determined the degree of freedom (df), 20, the t-value can be looked up in a standard table of significance. By doing so, the t-value is found to be significantly large. Therefore, from a statistical point of view, there is substantial difference between the mean scores of the control group and experimental group. Such marked difference confirms that the samples have been drawn from different populations. 


\section{Discussion of the Results}

Although the initial t-Test confirmed that there was only a minimal group difference at the outset of the study, the second one confirms the existence of a significantly marked group difference at the end of the study. By drawing a comparison between the pre-test and post-test mean scores of the control group and the experimental group, it is apparent that on the whole, the experimental group did noticeably better than the control group in terms of improvements in their reading skills.

Where reading sub-skills are concerned, it is interesting to note that the experimental group did substantially better than the control group in the three challenging parts of the reading paper (see Table 4). These are part one (gist understanding of real-world notices and reading for main message), part two (reading and identifying appropriate vocabulary), and part four (reading for detailed understanding and main ideas). Therefore, it can be argued that task-based writing instruction can impact positively on the reading skills of young teenage learners of English as a foreign language.

\section{Conclusion}

The idea that language learning is for communication purposes paved the way for a shift from traditional structural syllabuses and emphasis on rule learning towards communicative syllabuses and emphasis on interaction and communication. As a strong version of CLT, TBL is becoming increasingly popular among language authorities around the world as a flourishing method with its main focus on language use. Where language learning is concerned, some kind of reciprocal interrelationship has been acknowledged between reading and writing as two of the four language skills. Therefore, it can be argued that writing might have the potential to help learners of English, particularly young teenage learners to make improvements in their reading skills to an extent. Having conducted a quasi-experimental study with a control group and an experimental group and painstakingly analysed the results of the pre-test and the post-test through the t-Test, it is evident that task-based writing instruction impacts positively on the reading skills of young teenage EFL learners. Significant improvements are observed in their reading sub-skills that is, reading for gist, reading for specific information, and reading for detailed understanding. The results of the study suggest that task-based writing instruction can probably have a positive impact on the reading skills of other age groups, as well. However, there is clearly a need for further research.

\section{References}

Brown, H.D. (2001). Teaching by Principles - An Interactive Approach to Language Pedagogy (2nd edition). London: Pearson Education.

Carson, J., \& Leki, I. (1993). Reading in the composition classroom. Boston: Heinle and Heinle.

Guterman, E. (2003). Integrating written meta-cognitive awareness guidance as a psychological tool to improve student performance. Learning and Instruction, 13(6), 633-651. http://dx.doi.org/10.1016/S0959-4752(02)00070-1

Howatt, A. P. R., \& Widdowson, H.G. (2004). A History of English Language Teaching. Oxford: Oxford University Press.

Li, Y. (2000). Linguistic characteristics of ESL writing in task-based e-mail activities. System, 28(2), 229-245. http://dx.doi.org/10.1016/S0346-251X(00)00009-9

Littlejohn, A. (1991). Cambridge Skills for Fluency: Writing 1. Cambridge: Cambridge University Press.

Palmer, G. (2004). Writing Extra: A Resource Book of Multi-Level Skills Activities. Cambridge: Cambridge University Press.

Richards, J.C. (2006). Communicative language teaching today. New York: Cambridge University Press.

Stotsky, S. (1983). Research on reading-writing relationships: a synthesis and suggested directions. Language Arts, 60(5), 627-642.

Willis, J. (1996). A framework for task-based learning. Harlow: Pearson Longman. 